\title{
Undergraduate Research and Teaching Opportunities from a Transient Network Analyzer
}

\author{
Ronald O. Nelson, David C. Flegel, Brian K. Johnson, Herbert L. Hess \\ University of Idaho \\ Moscow, Idaho
}

\begin{abstract}
A Transient Network Analyzer (TNA) is a large, controlled hardware simulation environment for studying electrical faults. Background is presented on how the university acquired a TNA from a public utility and adapted it for use in teaching and research. System is described with specifications. Capstone design process combined with a solid funded followup serves as a means to leverage the creation of such large research tools. Details of ideas for design, implementation, projects, and data collection are presented.
\end{abstract}

Introduction

A Transient Network Analyzer (TNA) is a controlled hardware environment with which engineers can intentionally create and observe real electrical faults on a scale model power distribution system. A TNA has the main elements of a section of the commercial electrical grid, such as lines, sources, transformers, loads, instrumentation, and protection. There is a significant degree of flexibility for interconnection and instrumentation. Appropriate scaling of voltages, currents, impedances, and other quantities permit its behavior to safely mimic the transient performance of a section of the grid. Many utilities own such hardware. Larger TNAs have replaced smaller ones or, more frequently, advanced digital simulation systems have taken the place of TNAs. Occasionally, a TNA becomes available for university donation. The question then becomes how to install such equipment on limited university resources.

In this paper, such a TNA provided an opportunity for undergraduate research and teaching. Through a series of projects, the TNA was installed and outfitted for use in both research and teaching. By combining the enthusiasm and ideas of the capstone design process with a solidly funded followup, a working tool became available. This paper begins with a synopsis of TNA's history, background, and initial installation. Through a sequence of capstone design projects, the feasibility of tools and enhancements is investigated and a host of good ideas are discovered. Those ideas were incorporated into the TNA by a funded research team. Details of the TNA's performance and the design of research tools are presented in this paper. Applications for teaching, particularly at the introductory level, are also explained. In other words, scarce research money is leveraged effectively by a combination of the capstone design and a thorough followup process to yield a useful tool for both research and a broad range of teaching.

Background

Idaho Power Company designed and built a TNA to enable its engineers to analyze portions of its grid. After a period of service with the company, the TNA was donated to the University of Idaho in 1999. The Schweizer Engineering Company donated state-of-the-art protection equipment during the following year. Unlike its public utility applications, the TNA now 
supports research into fast protection and reconfiguration of warship electrical systems, projects funded by the US Navy. Instead of its historical analog interface, the TNA gets updated to include digital generation and control of faults, a power electronic implementation of them, and automated instrumentation for a greater data collection and analysis capability. The Navy lacks (but really needs) these capabilities in its network of university research partners.

In the course of installing, upgrading, and operating the TNA, it became a unique and powerful tool to teach undergraduate students the fundamentals of network operation and protection and to give them a vehicle for learning hands-on design of digital design methods and realistic behavior of electric power systems. Undergraduate involvement proved the norm from the very beginning. The TNA arrived on campus in a disassembled state, so the first project logically became assembly and testing. Ron Nelson, hired as a project engineer, performed most of the work. A team of three undergraduate students tested the TNA and documented its operation. The same team characterized the impedances of the major elements of the TNA, such as its transmission line segments. When they finished, the TNA was ready for its first projects, accomplished through undergraduate design work, to create the capabilities that the Navy needs.

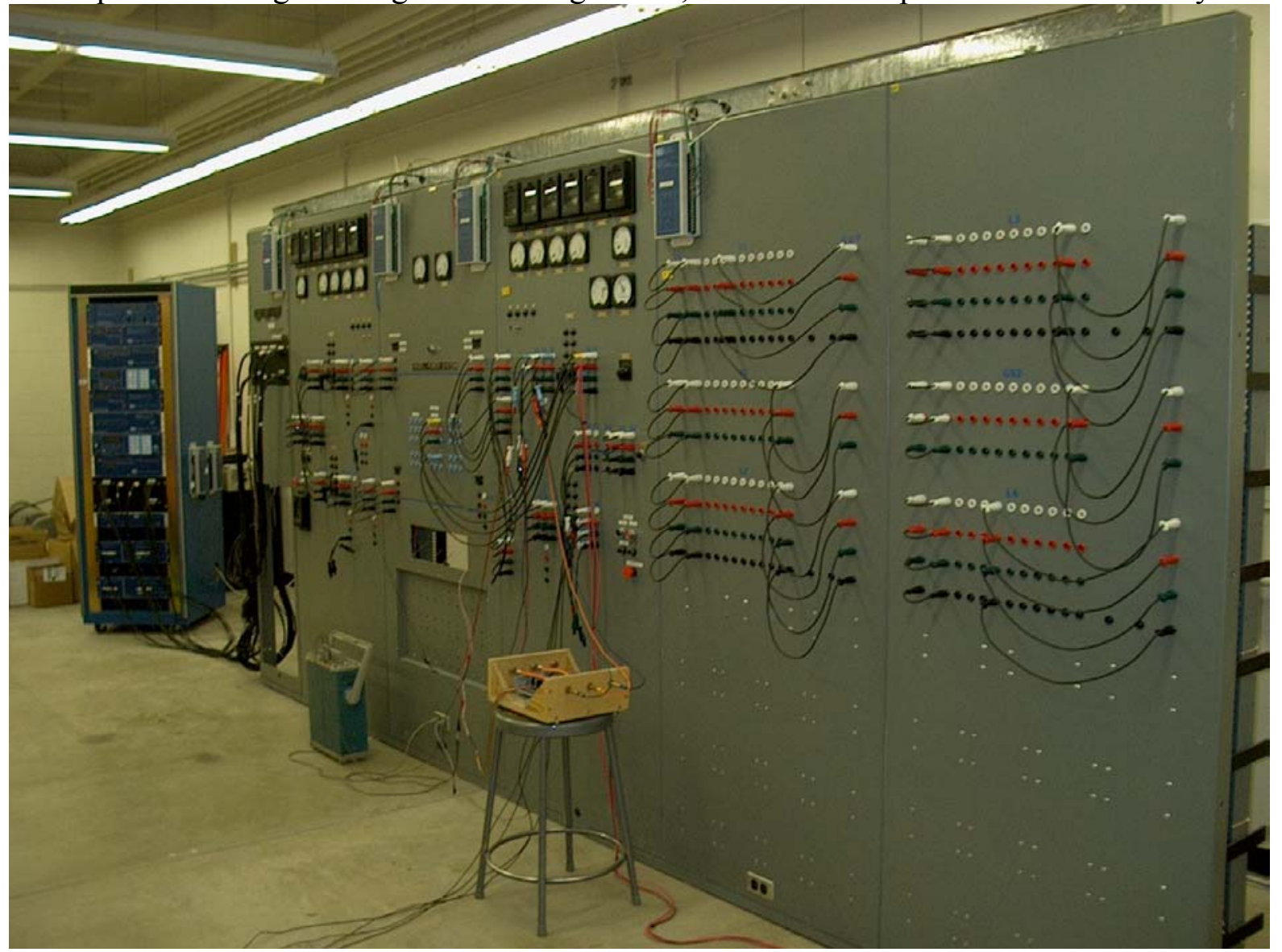

Figure 1. Transient Network Analyzer

\section{System Description}

The TNA is a small configurable electric power system. It has four tap selectable line segments and two source segments. A photograph is shown in Figure 1. 
A typical configuration is shown in Figure 2. The TNA operates at a nominal $120 \mathrm{~V} / 208 \mathrm{~V}$ three phase. Each line segment has voltage and current instrumentation: (current transformers (CT) and potential transformers (PT). It has mechanical circuit breakers with both manual control and remote control logic. The circuit connections are all done with patch cables, so many configurations and measurement taps are possible. All line models are currently single pi. Connected to the TNA is a rack of state of the art protective relays donated by Schweitzer Engineering Laboratories, shown in the rack at the left side of Figure 1. These components allow implementation and testing of a wide variety of standard protection schemes. The next round of improvements will include multiple pi section line models and fast-acting solid state circuit breakers.

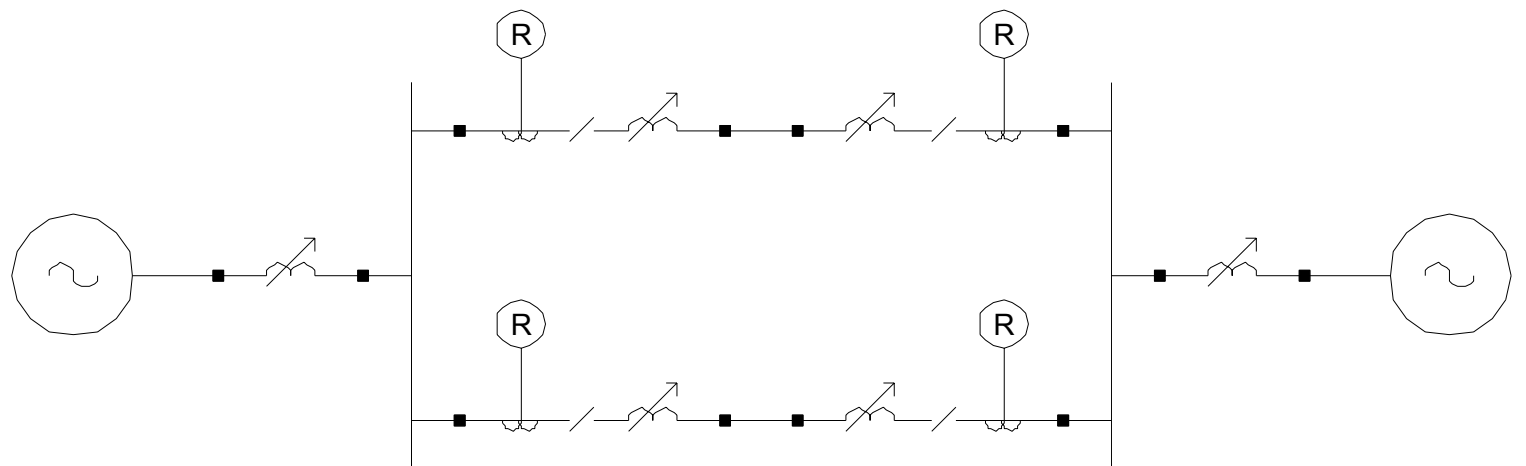

Figure 2. Typical TNA Configuration.

Central to the ability to perform analysis of specific transient scenarios is the implementation of a computer controlled fault generator. This component contains multiple banks of back to back thyristors that are activated at precise times and intervals. With the fault generator, complex multiple and progressive faults are modelled making real time voltage and current behavior during those events available for extensive analysis. Currently, only low-impedance faults are implemented, though a variable impedance fault capability is undergoing proof-of-concept testing as explained later in this paper.

Fault Generation

The fault generator had the following capabilities:

- Produces several types of faults including phase-to-phase, phase-to-phase-to-phase, phase-to-ground, double phase-to-ground, and three phase-to-ground

- Progresses from one type of fault to another when requested

- Produces up to three faults at separate locations simultaneously

- Begins faults within \pm 0.5 degrees (on a $60 \mathrm{~Hz}$ reference) of the specified time.

The fault generator was created through a process that has proven quite successful. First, a capstone project team designed and built a proof of concept. A funded research team immediately followed up, improving the design and installing the result. This overcame the problem of the capstone design team's fixed termination date, a situation that often lead to rushed and incomplete work. Nonetheless, the followup incorporated the new ideas and enthusiasm that such teams typically have. 
In this case, the design team proposed a combination of an Intel MCS96 series microcontroller and a Xilinx programmable logic device (PLD). This was an innovative idea at the time. The microcontroller provided the timing reference and sent fault data and other timing signals to the PLD. The PLD stored fault patterns and when requested, used the timing signals from the microcontroller to

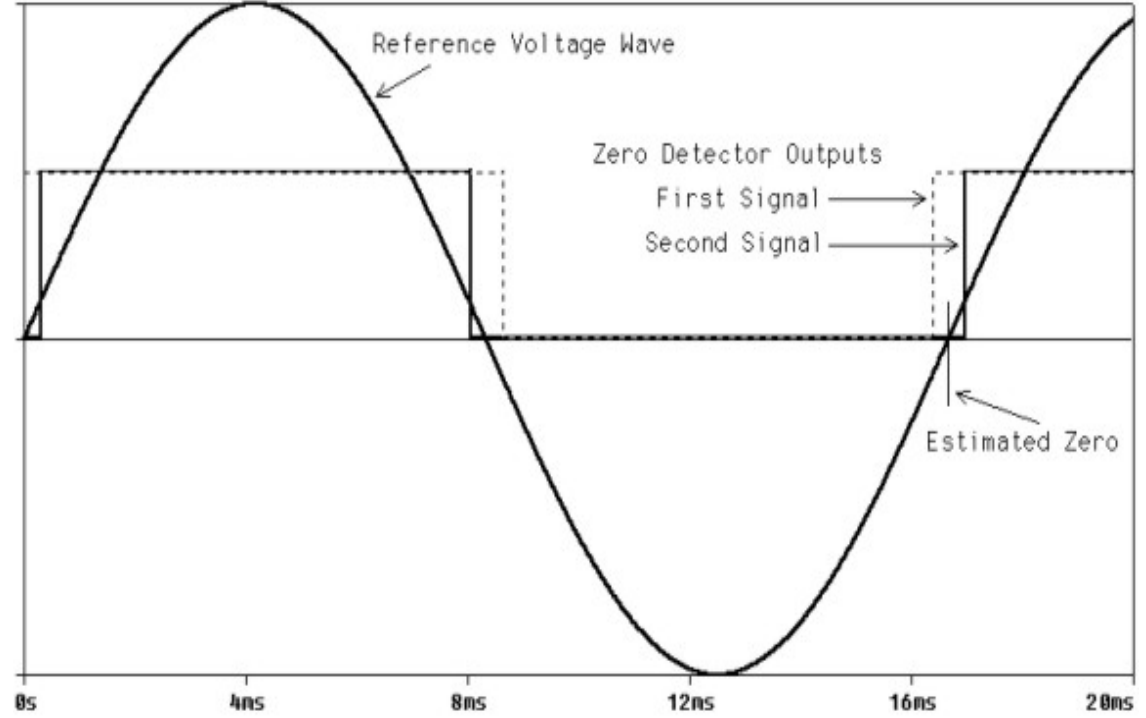

Figure 3. Zero Detection Waveforms

initiate the faults in the system. The PLD also generated the precise gate signals required by gate driver boards to fire the thyristors that conducted the fault current. The design team proposed a twofold zero detection system as the basis for timing. A primary zero-detect circuit provided accurate information of the ac voltage waveform zero crossings as shown in Figure 3. An innovative dynamic hysteresis method and an error-reduction algorithm operated on the "first signal" and "second signal" values to improve accuracy to within specifications. A secondary zero-detection, based on current zero crossings, used the same innovations to provide timing signals after fault initiation, when primary zero detection was lost. Gate drivers were purchased from Enerpro, a decision that saved much design time and gave superbly reliable and accurate gating of the thyristors that carried the fault current. Details of this are presented in [1].

A software interface was written that allowed the user to enter in the fault data desired and the command to start the fault(s). This was implemented in Visual Basic on a PC running a version of the Microsoft Windows operating system. Communication was performed using the RS232 serial communications protocol which handled downloading of fault data to the microcontroller upon the command to start the fault. The control window is shown in Figure 4.

The funded design group built on these ideas. Streamlining the software and reducing the size of the PLD were their primary contributions. Using a 555 Timer cut the required PLD size by more than $80 \%$ and standardized the gate drive system voltage. The remaining PLD functions fit into a new microcontroller that had more interrupts and more output pins. A diagram of the new logic is shown in Figure 5. A greatly improved startup algorithm overcame the inadequate method that the capstone design team hurriedly added as time grew short. Software fault tolerance was improved. The number of progressive fault steps was increased from three to 255 . A clear and restrike capability was added. The software of the microcontroller was rewritten to allow for changes and growth that will not affect overall functionality, such as the planned addition of a variable fault impedance capability. All software has been designed to allow text (including remote RS232 interface) or graphical user interface. 


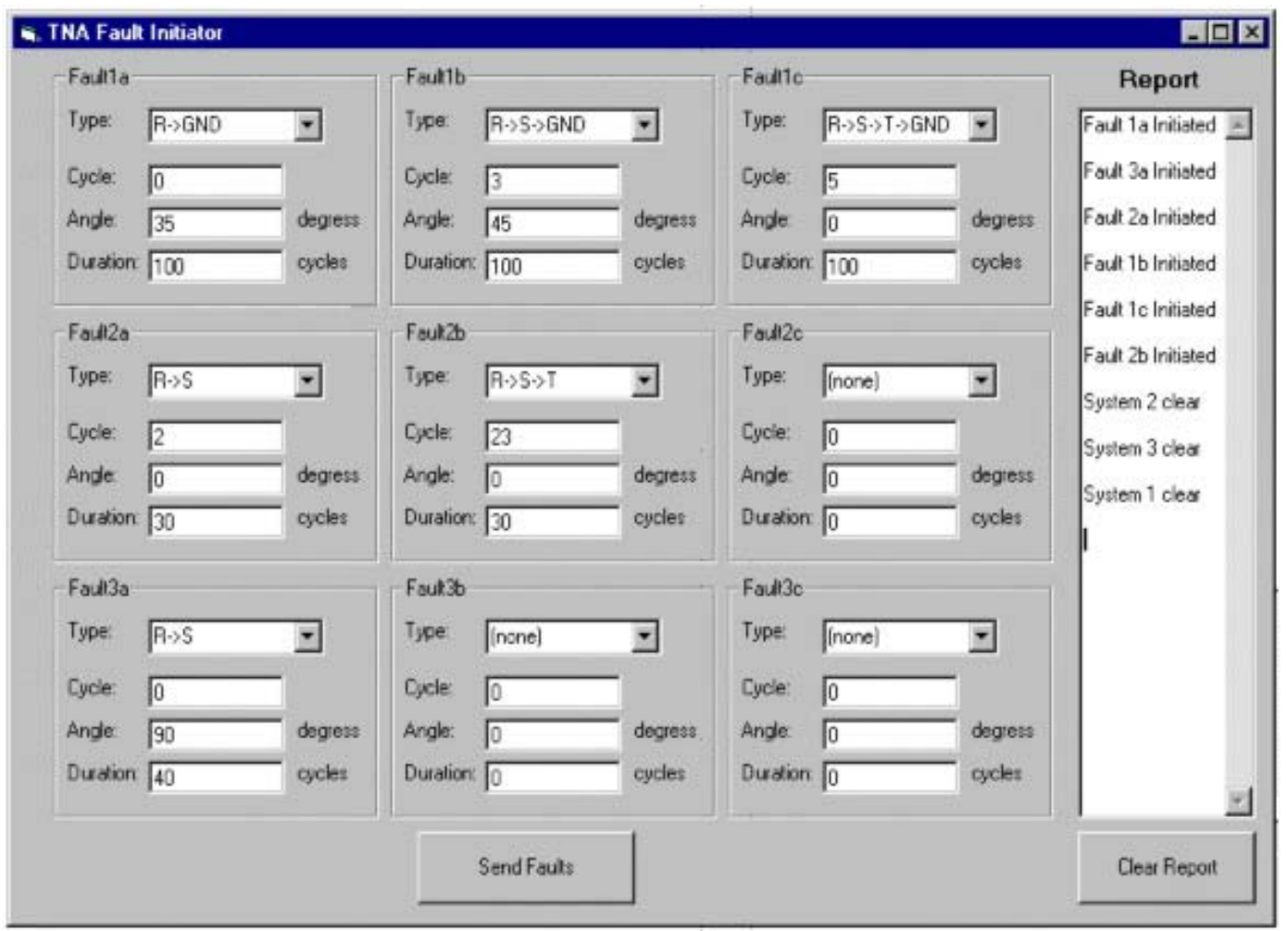

Figure 4. Control Window for Graphical User Interface

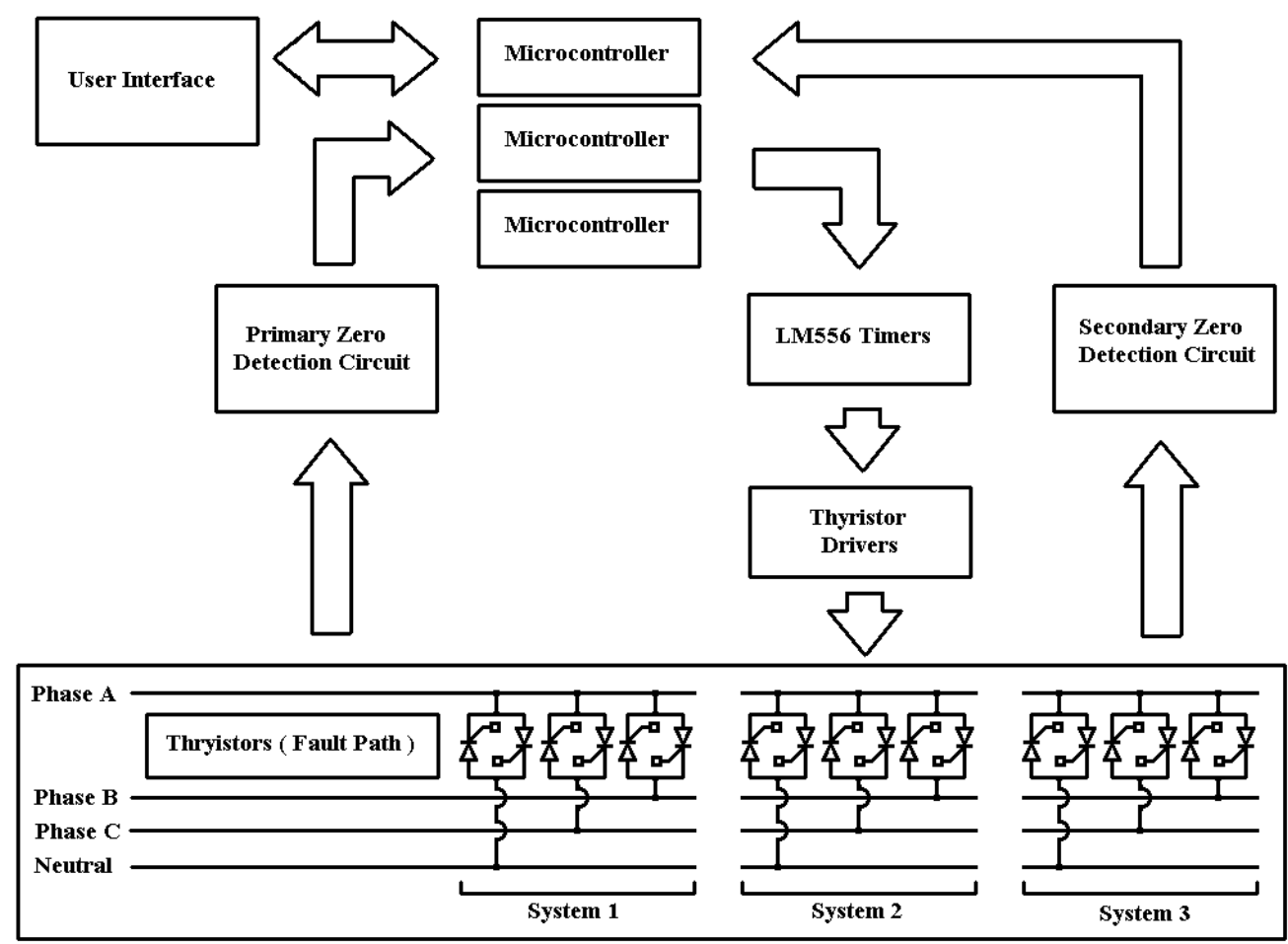

Figure 5. Control Design for Improved Fault Generator 
Some results included below are plots of voltage and current during two fault scenarios. The first, in Figures 6 and 7 are depictions of the three phase voltage and current waveforms during a progressive fault that implements six cycles each of a line to line fault followed by a line to line to ground fault after which all three phases are faulted to ground. The first fault is initiated at 90 degrees (on a sine reference) into the voltage between line $\mathrm{a}$ and line $\mathrm{b}\left(\mathrm{V}_{\mathrm{ab}}\right)$. The pre-fault condition does include some small amount of load current.

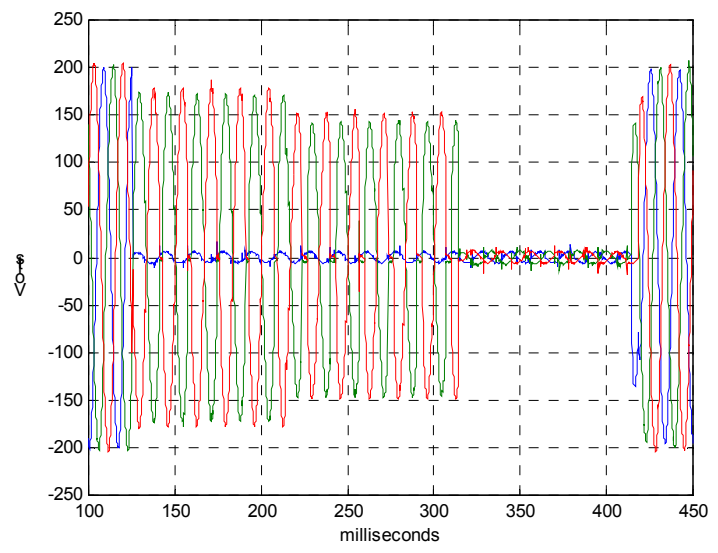

Figure 6. Progressive Fault Voltage

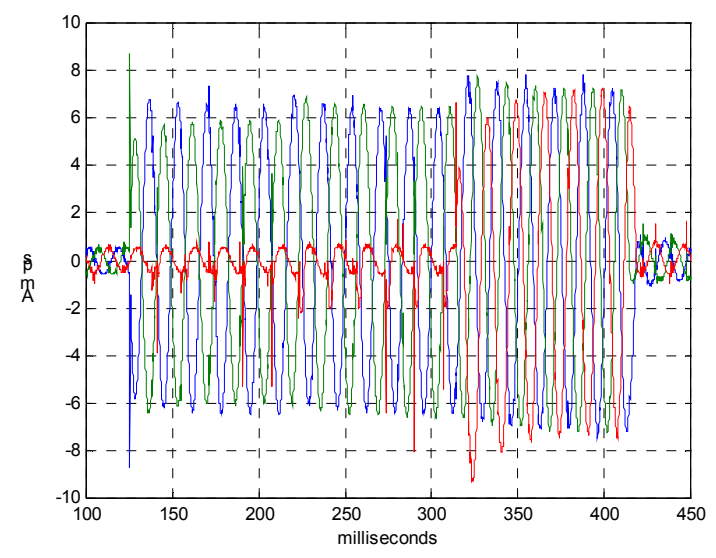

Figure 7. Progressive Fault Current

The second set of plots, found in Figures 8 and 9, show voltage and current associated with a line-to-line fault that is subsequently cleared by a protective relay. In this case the pre fault load is high enough to be within $70 \%$ of the relay's trip point. The SEL 351S protective relay is set to trip on an instantaneous overcurrent of 8 amps.

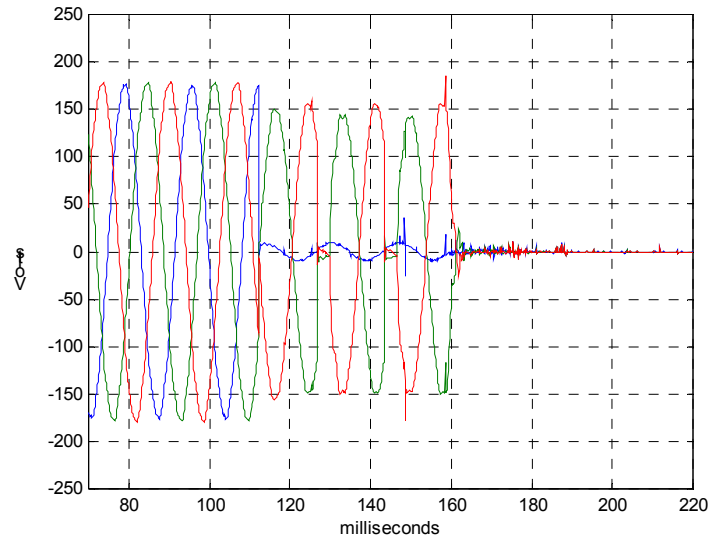

Figure 8. Fault Cleared: Voltage

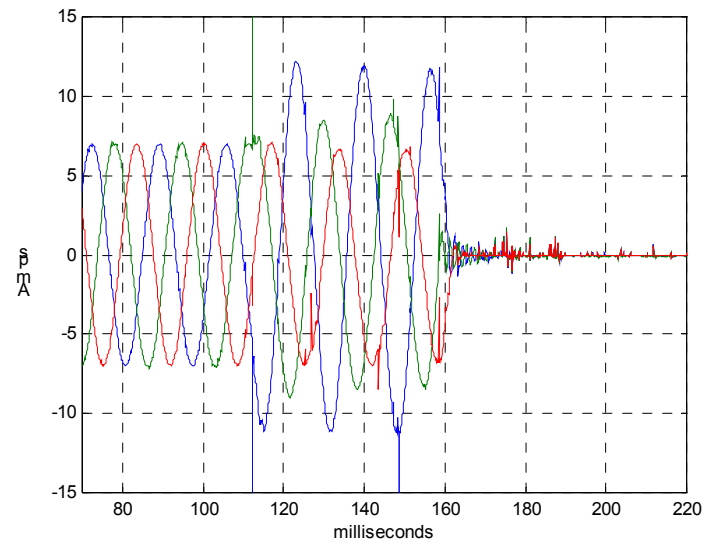

Figure 9. Fault Cleared: Current

The method for design and learning employed for the fault generator gave a fruitful balance to the effort. Capstone students received a challenging design project, one in which they did innovative, cutting-edge work. The research team received the benefit of their ideas and enthusiasm. The end result is an exceptionally useful piece of laboratory hardware that has overcome the problems typical of "homemade" solutions. 
Fault Impedance

The TNA was originally designed for relay engineers at Idaho Power Corporation to test settings on protective relays. Their transmission system has many long transmission lines with series compensation. As a result, the TNA had series capacitors available for all of its line segments. It was possible to control the power flow through transmission lines by using a combination of series capacitors, phase shifting transformers, and mechanical switching. These three elements relied on mechanical switching, yielding slow response times. However, by implementing power electronic based Flexible AC Transmission Systems (FACTS) technologies such as a Thyrsistor Controlled Series Capacitor (TCSC), fast and control of steady state power flow in transmission systems could be reliably achieved using static power electronic devices. This resulted in a transmission line that was more efficient and has increased power transmission capabilities. Also improved are transient stability, voltage stability, damping of certain power oscillations, and subsynchronous resonance damping.

Concurrently with the fault generator, a capstone project team designed and built a TCSC. The project objective was to design a TCSC system that is economical, robust, efficient, and easy to operate. The team used simulation to obtain a reasonable limit of 40 degrees for the conduction angle. They limited their design to an open loop control with user input. A microcontroller was at the heart of the system, creating firing signals for the TRIAC from a timing algorithm based on a digital phase-locked loop.[2] The same gate driver boards were used for the same reasons. Each of these issues were similar to those encountered by the fault generation team. Consequently, the teams often shared insights, seeing the same issues in two different contexts. The TCSC was successfully developed and tested. The experimental results closely matched the simulated waveforms. Details are presented in [3].

In this case, however, the results were not immediately passed to a funded design team for implementation. The success of the fault generator had shortened the overall research critical path. The next step became including variable series impedance in the faults that were being generated. Because the TCSC is a variable series impedance, a new capstone design team began to combine the results of the two projects into a more practical and realistic fault generator. A funded research team will follow up on the variable impedance fault generator design (and later on the TCSC also). The ability to initiate faults having finite impedance improved the TNA as a research tool and as a teaching because these variable impedance faults more closely resembled those seen in public utility transmission and distribution systems. By building on ideas as they appear, the TNA's design teams have created an effective learning tool.

Data Capture System

The data capture system was another example of the successful design method. The computercontrolled, automated data capture and logging equipment is another valuable element of the TNA model power system. The plots shown in Figures 6-9 were recorded with an eight-channel system developed in the course of a previous project. It used commercial software package $\left(\right.$ LabView $\left.{ }^{\circledR}\right)$ and common data capture hardware purchased from National Instruments. Now a funded student is near the first phase of completion of a faster (1.25 M samples per second) 32channel system. This improved system will include an extensive graphical user interface to provide flexibility in viewing the data and saving it to file for post processing. The new system also will have the capability of synchronizing with the fault generator and the other components 
of the system, providing the ability of setting up a specific fault protection - data capture scenario that can be started with a single mouse click and proceeds under automated control from that point to its finish. The idea to do this came as a result of the inconvenience encountered when synchronizing data collection with fault generation in one of the capstone projects. Now the data collection exhibits simplicity of operation as well as being repeatable and easily modifiable performance.

Classroom Applications

The TNA was initially intended for research and perhaps an occasional demonstration for advanced students. However, the TNA has proven helpful in a range of electric power courses and labs, from the initial undergraduate circuits courses through the curriculum to the advanced graduate power system protection course. Automated digital generation and control of faults was at the heart of this.

In the initial circuits course syllabus, ac power is a major topic. A great deal of time and paper is spent learning the fundamental behaviors and analysis methods. Supporting laboratory work may be somewhat sterile, often limited by equipment and safety considerations. The TNA has changed this. Students begin on paper, as they have done in the past, performing the calculations appropriate to a steady state power system such as shown in Fig. 1. They repeat the process on paper for a fault in the system, typically somewhere on one bus. However, now they follow up on the TNA: synchronizing the system to the utility, taking steady state measurements, initiating the fault, and recording the results. The presence of light bulbs as loads and indicators dramatically illustrates what their calculations mean. The TNA has the flexibility to permit a different set of circumstances for each group or several circumstances for a given group. Seeing the digital controls (from the computer screen) and knowing that the fault generation and control is all digital, designed by undergraduates, clearly gains attention. Interest in electric power engineering has grown among the undergraduates, as assessed by enrollment in subsequent "power" course.

The TNA gets revisited in the mandatory junior-level energy conversion course. The vehicle is a laboratory demonstration. This reinforces what students have seen in their circuits course. The TNA appears again in the power systems course at the senior level to verify power flow concepts. The TCSC has been used for class demonstrations in power electronics and will be used in a graduate level utility applications of power electronics course. The TNA also supports the advanced protection course for the graduate students. Currently being developed is a design exercise wherein the graduate students design a protection algorithm using software donated by Schweitzer Engineering, download it to the TNA using a web interface, and then test it on the TNA. The Schweitzer equipment has a datalogging capability that returns test results to the students. All this is done from a remote web interface. The student never physically enters the laboratory. A future paper will report on these applications and will more thoroughly assess the effect that the TNA has upon student interest in electric power engineering.

As mentioned already, the TNA has provided realistic design problems for several capstone design teams. It will continue to do so as new capabilities for the TNA are proposed. The model of having capstone design teams perform the proof-of-concept has been a successful one when followed up by a funded research effort to consolidate and implement what the design team 
showed. The capstone design team inexpensively found whether an idea is feasible; the research effort then efficiently implemented those ideas that proved reasonable. In less than two years, more than a dozen undergraduates and several graduate students have been involved in these implementation efforts. Video presentations of capstone design projects are available from the last author of this paper (Hess).

\section{Research Projects}

A substantial part of the cost of restoring the TNA has been underwritten by research projects. Capstone design projects have been an effective way to leverage this money, a particularly useful practice at a university where undergraduates are plentiful, but graduate students have been scarce. The primary source of this money has been a project funded by the US Navy to develop improved system protection and reconfiguration schemes for shipboard power systems. Their desire to investigate multiple faults at a given location drove the development of a fault initiator capable of initiating simultaneous faults. The model of capstone design followed by funded research effort leveraged the resources. Not every research topic or new tool lent itself to investigation by a capstone design team. Examples of funded projects enabled by the TNA are as follows:

- The TNA was designed to simulate a overhead transmission system with long transmission lines, a new set of cable models needs to be added to represent the shorted cables used in shipboard systems. A team of funded undergraduate and graduate students worked on developing this aspect, creating a series of coupled pi sections to represent each cable segment.

- Solid state circuit breakers controlled by relays, a project that could be done either by a graduate student or by the capstone design with followup presented in this paper. In this case, an interested graduate student trumped the decision.

- Adding energy storage in the form of flywheel energy storage. Again, an interested graduate student encouraged a traditional research decision.

\section{Conclusions}

A Transient Network Analyzer (TNA), donated by Idaho Power Company and intended as a useful research tool also became a valuable tool for teaching. Through a series of capstone design projects followed up by funded research, important tools for studying fault behavior in

electric power systems were added. Research was leveraged and both undergraduate and graduate learning was enhanced. The projects served as a learning tool. Demonstrations and laboratory exercises were then developed for students from beginners in the circuits course to graduate students, both on-campus and through outreach. The system has become a useful tool for both research and a wide range of realistic teaching.

\section{Acknowledgements}

This research was supported by a grant from the United States Surface Warfare Center under the Experimental Program to Stimulate Competitive Research (EPSCOR). Idaho Power Company donated the TNA. Schweitzer Engineering Company donated the state-of-the-art relaying and protection equipment. The following contributed to the TNA installation project: Greg Klemensrud, Joe Fugate, Scott Schellhammer, and Ivan Anderson. The following contributed to the TCSC project: Mark Lippencott, Brandon Enevold, and Mike Hocklander. The following contributed to the Fault Generator project: , Ken Hollinger, Jon Leman, and Dan Gordon. 


\section{References}

[1] D. Gordon, K. Hollinger, J. Leman, B. Johnson, H. Hess, R.Wall, “TNA Fault Controller," Proceedings of the 2001 North American Power Symposium, College Station, Texas, 17 October 2001, pp. 437-443.

[2] R. Wall and H. Hess, "Design and Microcontroller Implementation of a Three Phase SCR Power Converter", Journal of Circuits, Systems, and Computers, Vol. 6, No. 6, pp. 619-633, December 1996.

[3] J. Leman, D. Gordon, and K. Hollinger "Zero Detection For Precision Fault Control," University of Idaho unpublished research report.

[4] M. Lippencott, B. Enevold, M. Hocklander, "Thyristor Controlled Series Capacitor," University of Idaho unpublished design report.

RON NELSON received his MSEE degree from the University of Idaho. He is on staff with the MRC Institute there as a Research Associate. His interests include electronic control of power system stability, especially in the venue of distributed generation systems, automated instrumentation systems, and computational electromagnetics.

DAVID C. FLEGEL received the B.S. degree in Computer Engineering from the University of Idaho in December of 2001, and is currently progressing towards a M.S. in Electrical Engineering. His interests are in embedded control and signal processing applications with an emphasis towards power systems.

BRIAN K. JOHNSON received the Ph.D. degree in electrical engineering from the University of WisconsinMadison in 1992. He is currently an Associate Professor in the Department of Electrical Engineering at the University of Idaho, Moscow, ID. His interests include HVDC transmission, FACTS, custom power technologies, energy storage, utility applications of superconductivity, power system protection, electromagnetic transients in power systems, and real time simulation of traffic systems. Dr. Johnson is a member of CIGRE and is a Professional Engineer in Wisconsin and Idaho.

HERBERT L. HESS received the PhD degree in Electrical Engineering from the University of Wisconsin-Madison. He joined the faculty of the University of Idaho in 1993, where he is Associate Professor of Electrical and Computer Engineering. His interests are in electronic conversion and control of electrical energy in such applications as electric utilities, electric machine drive systems, power supplies for electronic equipment, and microelectronic power devices and systems. He is Chair-Elect of the Energy Conversion and Conservation Division of ASEE. 